\title{
LOS COLORES Y SU SEMÁNTICA EN LAS EXPRESIONES FRASEOLÓGICAS ESPAÑOLAS
}

\begin{abstract}
Szalek Jerzy, Los colores y su semántica en las expresiones fraseológicas españolas [Colors and their semantics in Spanish idiomatic expressions]. Studia Romanica Posnaniensia, Adam Mickiewicz University Press, Poznań, vol. XXXII : 2005, pp. 87-96. ISBN 83-232-1465-4, ISSN 01372475.
\end{abstract}

Analysis of Spanish idiomatic expressions containing chromatic components provides us with more knowledge of the structure of the modern Spanish phraseology. Studying the difficult to perceive semantic interdependence occurring between the compounds of a given type, allows us to draw a few vital conclusions and also to present the specific character of the Spanish language in respect of perceiving and understanding the world through the symbois of colors (Sp."idiosincrasia espanola") . From the point of view of phraseology, Spanish phraseological units containing colors display various degrees of both stability and idiomaticity and their ultimate meaning can be diverse; on occasions they can even be opposite in meaning in the frame of a given type.

Será una perogrullada decir que los colores que nos rodean poseen múltiples valores simbólicos. Sin embargo, esta simbología no es homogénea en nuestra realidad humana ni en dimensiones temporales ni espaciales. A lo largo de los siglos el significado de los colores en la mente de los hombres ha cambiado de vez en cuando en dependencia de diversos factores, tanto extralingüísticos como lingüísticos. La codifícación semántica de cada uno de los colores puede ser poco parecida si analizamos algunas de las lenguas habladas en ámbitos lejanos o totalmente diferentes al nuestro europeo. En opinión de los psicólogos, las propiedades fisicas de los colores influían en el hombre desde sus orígenes, creando una especie de códigos. Asimismo, el hombre, muy a menudo, inventaba, en su larga y compleja historia, varios sistemas de comunicación mutua, apoyándose en el espectro visible de los colores. Baste recordar aquí los colores de guerra en el rostro de los indios americanos y, en la actualidad, muchos sistemas de señalización (p.ej. los de tráfico) o escalas de colores utilizados en las ciencias (p.ej. en los mapas, química, etc.). 
El hombre utiliza los colores no solamente con fines prácticos, los utiliza también en la misma creación lingüística, en la literatura y la poesía. El uso de los nombres de los colores les permite a los poetas evocar positivamente o negativamente un fenómeno, un lugar, una persona o una cosa, etc. (véase a modo de ejemplo la creatividad poética de $S$. Grochowiak, especialmente en cuanto al uso del color "dorado", Kurek 1997: 132-147). Uno de los poetas españoles más destacados, Antonio Machado, describía sobre Soria: "(...) colinas plateadas, grises alcores, cárdenas roquedas $(\ldots)^{\prime \prime}$.

El análisis de los colores fijados en unidades fraseológicas puede ser una fuente inagotable de información sobre los procesos de codificación semántica llevados a cabo dentro de un sistema lingüístico dado. En la lengua española, al igual que en otras lenguas europeas, abundan fraseologismos y otros dichos que contienen en su estructura un componente cromático, p.ej., la paremia o refrán:

de noche todos los gatos son pardos

advierte, lo que aseguran también los mismos físicos, que el ojo humano no suele captar por igual todos los colores si cambia la luz y que las personas y cosas se confunden o igualan, cuando anochece.

Al referirse al léxico del color, Marina (1999: 191-195) asegura bien que es "un dominio semántico de extraordinario interés porque permite estudiar con precisión los tres niveles del lenguaje: la segmentación léxica (es decir, la manera cómo se han dividido los colores para nombrarlos), la percepción subjetiva (el significado, la experiencia designada) y el fenómeno físico (el referente)".

Nosotros, en este estudio, intentaremos concentrarnos primordialmente en el nivel semántico, tratando de poner de relieve lo que podríamos llamar una idiosincrasia española.

De un continuo que es el espectro de los colores, las diferentes lenguas han escogido distintos colores, p.ej., las lenguas románicas han designado las siguientes: blanco, negro, rojo, azul, verde, amarillo, gris, marrón, rosa y violeta, de los que los tres últimos son - en opinión del mismo autor - que sigue a su vez a A.M. Kristol (1978), "innvoaciones comunes a las lenguas románicas" (op. cit., p. 192).

Brent Berlin y Paul Kay (1969) suponen que hay, por lo menos, once categorías de colores básicos: rojo, verde, azul, amarillo, negro, blanco, gris, naranja, púrpura, marrón, rosado. Asimismo, en la mayoría de las lenguas examinadas, el léxico cubre, más o menos, todo el espectro cromático, independientemente de la cantidad de las voces que se utilizan para designar los colores. Además, si aumenta el número de palabras inventadas para cada una de las categorías, no cambia su orden en las diferentes lenguas. De ahí, se cree que el hombre tiene una predisposición natural de carácter cognoscitivo (cognitivo) para tratar de agrupar los colores en algunas categorías básicas (véase Marina (191-195), quien sigue algunos de los estudios más recientes). 
El caudal léxico español contiene toda una gama de nombres de colores tanto simples como derivados, así como objetos con rasgo semántico de color, p.ej.:

amarillento (que tira a amarillo),

verdoso (que se asemeja al color verde),

azulado (de color parecido al azul),

grisáceo (que tira a gris),

rojizo (que tira a rojo);

grana (de color rojo oscuro),

limón (color amarillo brillante semejante al del limonero),

naranja (semejante al color del fruto de naranja),

violeta (que es morado claro parecido al de las flores denominadas violetas), etc.

Además, tenemos en español muchísimos nombres de colores que expresan matices intermedios, que pueden ser compuestos 0 unidades fraseológicas y que constan de, por lo menos, dos elementos, p.ej.:

verde botella (color verde intenso oscuro),

verde esmeralda (color de la piedra preciosa esmeralda),

verdemar (verdoso como el mar),

verdinegro (de color verde oscuro que tira a negro),

azul celeste (azul muy claro), etc.

Todo esto puede darnos pistas suficientes para llevar a cabo un pequeño análisis (o repaso) de algunas significaciones conjuntas que contienen los fraseologismos españoles con componente cromático. En primer lugar, hay que advertir que la percepción subjetiva de los colores por parte de los hablantes nativos del español no es necesariamente la misma que la experiencia de los demás pueblos europeos, aunque, por lo general, no difiere tanto del paradigma cultural europeo (véase, p.ej., Arcaini 1993).

Tanto en español como en otras lenguas europeas es característico el rasgo semántico de contraste que hay entre "lo claro" y "lo oscuro", entre "lo blanco" y lo "negro", que proviene, sin duda, de nuestra percepción primitiva del día y de la noche (decimos p.ej.: "ser como la noche y el día", "parecerse como el día a la noche, etc.). Ahora bien, pongamos algunos ejemplos de unidades españolas con los componentes en cuestión:

"a las claras" (con claridad),

"por lo claro" ( $\sin$ rodeos, de modo claro),

"de claro en claro" (en vela, sin la posibilidad de conciliar el sueño),

"poner (u.p.) en claro (algo) (aclarar, explicar alguien algo),

"cantar claro" (decir la verdad o confesarla),

"cantárselas (u.p.) claras (a alguien) (decirle a alguien algo abiertamente, una queja, opinión, etc.),

"más claro que el agua" (claro y seguro), 
"estar blanco" (estar uno sin antecedentes penales), etc.

"blanco y migado, leche" (algo que es muy evidente),

"blanco como el armiño" (muy blanco),

"un caballo blanco" (una persona protectora),

"jinete del caballo blanco" (aparece donde puede presentarse la muerte),

"blanco como un difunto" [como un cadáver, como el mármol], etc.

"estar en blanco" (no saber nada sobe algo), etc.

"estar (u.p.) a oscuras (sin comprender algo);

"pasar de castaño oscuro" (situación enojosa o grave e intolerable),

"estar negro" ["verse uno negro"] (verse uno en grande apuros),

"tener la negra" (tener mala suerte)

"pasarlas negras" [vérselas negras], [versc negro] (verse en situación muy complicada o comprometida),

"mercado negro" (mercado ilegal),

"oveja ncgra" [oveja descarriada] (persona de mala conducta dentro de una comunidad o un grupo)

"estar (ponerse) negro" (enfadarse; estropearse), etc.

La simbología de los colores claro y oscuro, blanco y negro es bien conocida.

El claro sugiere certeza y seguridad, comprensión y transparencia; el oscuro es todo lo contrario. El blanco es el color que simboliza en términos generales la luz, la pureza y la inocencia y el negro, el mal, la mala suerte, el pesimismo, los problemas, la tristeza, lo sombrio, la muerte, etc. Sin embargo, al analizar detalladamente las unidades fraseológicas españolas con componente cromático hay que observar que sus significados pueden ser muy diversos y hasta contradictorios:

"quedarse en blanco" (chasqueado, frustrado),

"estar en blanco" (estar ignurante de algo),

"estar sin blanca" (no tener dinero),

"hacer de lo blanco negro" (confundir),

"pasar la noche en blanco" (no dormir).

En comparación con el componente "blanco", el "negro" da en las expresiones fraseológicas españolas un sentido semánticamente más estable, casi siempre con semas negativos, excepto algunas unidades denominativas del tipo:

"espada negra" (una espada sin corte y con un botón en la punta),

"agujero negro" (en el espacio cósmico cuerpo de extrema densidad y gran atracción gravitatoria),

"caja negra" (dispositivo que registra el funcionamiento de un avión en vuelo), etc.

Paradójicamente, "negro" es, en algunos paises hispanoamericanos, una voz de cariño usada entre personas de mucha confianza.

Sanmartín Sáez (1998: 245) registra en su Diccionario de argot, la unidad "tenerlo [1levarlo] claro" en el sentido de "ser, resultar alguna cosa, situación difícil, problemática". El componente "claro" cambia aquí el significado adquiriendo el de 
oscuro, es decir, "problemático". "Lo llevas claro, nunca aprobarás mientras yo sea la profesora" (op. cit., 1998: 245).

Otro fenómeno semántico de las unidades con elemento de color está ligado con el proceso de señalar y/o de graduar una cosa. Muchas expresiones cromáticas que, por lo general, tienen homófono libre o literal describen o denominan estados, situaciones o fenómenos de la vida humana o social que suponen cierta graduación de rasgos o, por lo menos, su clasificación. En el campo de los deportes, concretamente en el fútbol, distinguimos, por ejemplo, "tarjeta amarilla" y "tarjeta roja", respectivamente.

Otros ejemplos de unidades fraseológicas escalares de este tipo pueden ser los siguientes:

judias blancas/judias verdes,

luz verde [dar/tener luz verde]/luz amarilla/luz roja,

pimiento rojo, pimiento verde, vino blanco/vino tinto/vino rosado, etc.

En el antes citado diccionario, Sanmartín Saéz (1998:106) comenta que: "(..) cuando se detiene a un sujeto, se averigua si está blanco "sin antecedentes", verde, "con antecedentes" o rojo, "en busca y captura"".

Estas graduaciones cromáticas de cosas y fenómenos en nuestras actividades cotidianas demuestran la actuación de una continua interrelación entre el hombre y los colores. El hombre aprovecha los colores para expresar toda una serie de situaciones que normalmente sería difícil describir utilizando otros signos o palabras.

En español existen muchisímos fraseologismos especializados con componente cromático, mediante los cuales es posible reflejar las emociones u otras situaciones más sutiles. Esto se refiere al espectro de diferentes colores, p.ej.:

"gramática parda [saber, tener gramática parda]" (astucia y sabiduría en una situación difícil)

"pasar del rosa al amarillo" (cambio de humor súbito e inespcrado),

"estar (u.p.) amarilla [blanca, pálida] como la cera",

"comerse un marrón" [pillar/coger con el marrón], [ser algo un marrón], [caerle a alguien un marrón] (estar envuelto en un acto delictivo, pagar injustamente algunas responsabilidades),

"verlo todo de color de rosa" (ser muy optimista),

"pasarlas moradas" (padecer u.p. muchas dificultades),

"estar alguien verde" (no estar preparado, no estar maduro),

"ponerse [estar rojo] como un tomate [una amapola]" (ruborizarse, avergonzarse),

"ponerse morado" (comer con exceso),

"estar rojo" (estar en busca y captura),

"erudito(s) a (de) la violeta" (personas afectadas o cursis con pocos conocimientos, una especie de diletantes).

Por lo general, los colores cálidos, en contraposición con los oscuros y especialmente con el negro, transmiten en español algo positivo, bueno y optimista. Esto 
podemos confirmarlo siempre en líneas generales, porque hay también fraseologismos y algunas expresiones que poseen connotaciones diferentes y hasta contradictorias, p.ej.:

"cstar al rojo vivo" (encontrarse en estado de máxima excitación o crítico),

"no hay rosas sin espinas" (no hay placer sin disgustos o dolores),

"ponerlo rojo a alguien" (hacer que alguien se avergüence),

"viejo verde" (persona de edad avanzada con inclinaciones lascivas o lujuriosas),

"chiste verde" (chiste obsceno, con contenido sexual),

"números rojos" [entrar en números rojos] (saldo negativo cn una cuenta"), etc.

Por lo que podemos observar, en el proceso de fraseologización de las unidades con componente de color, las asociaciones significativas entre sus palabras constituyentes pueden resultar muy oscurecidas y hasta opacas. En algunos casos, la motivación es poco probable, especialmente desde el punto de vista sincrónico. Sin embargo, algunas aproximaciones a los significados comunes a nuestro ámbito cultural europeo, así como algunos análisis diacrónicos, evidencian diversos procedimientos semánticos a los que han sido sometidos estos fraseologismos.

Tomemos a modo de ejemplo, algunas unidades donde se percata el proceso de envilecimiento semántico:

"viejo verde", "chiste verde".

El color verde parece un buen ejemplo, porque al crear algunas unidades fraseológicas españolas les da un sentido unitario altamente idiomático, poniendo de relieve tanto la idiosincrasia de las expresiones como la diversidad significativa, así como la múltiple idiomaticidad.

Es curioso que hasta casi finales del siglo XVII el verde asociado con la palabra "viejo" guardaba su significado principal de "lozano", "sano", "juvenil". El envilecimiento, que se produjo bien entrado el siglo XVIII hizo cambiar totalmente la estructura semántica del dicho según el esquema:

"vicjo verde" [+persona de edad] [+masculino] [+vigoroso, juvenil, joven]

("un viejo que tiene vigor de mozo" según Covarrubias, Tesoro de la Lengua Castellana) $\rightarrow$ "viejo verde" [+persona de edad] [+masculino] [+obsceno] [+procaz] (persona de edad avanzada con inclinaciones lascivas o lujuriosas), (sinónimo en sentido directo: viejo libidinoso).

Antes de producirse este cambio, el sema [tobsceno] se aplicaba al color "colorado" o "rojo" (es decir, a los colores de la pasión y del fuego), (véase p.ej.: Irribaren 1997: 270, Buitrago 2003: 814).

El significado de "darse/pegarse u.p. un verde (de algo) es de "disfrutar de algún placer hasta hartarse" (cf. Varela, Kubarth 1994: 286), aunque en el lenguaje de los delincuentes quiere decir "tocarse con propósitos libidinosos" (compárese Sanmartín Saéz 1998: 850). 
La idea de "inmadurez" de lo verde prevalece en la unidad "estar verde". Es curioso que en la delincuencia significa, lo que hemos mencionado ya, "tener antecedentes penales".

Otras unidades con "verde" en la lengua española moderna son las siguientes:

"poner u.p. verde a alguien" (criticar severamente a alguien),

"dar (tener) luz verde (permiso, autorización),

"verde y con asa(s) (indica una evidencia),

"iverdes las han sega(d)o! (un rechazo o negativa),

"la mancha de (la) mora con otra verde se quita" (unidad paremiológica que se refiere al

"mal de amor" en el sentido de "un clavo saca otro clavo"),

"a buenas horas mangas verdes" (cuando algo llega demasiado tarde),

"billete verde" (el de mil pesetas),

"zona verde" (terreno con arbolado o parques),

"maillot verde" (especic de camiseta deportiva),

"mole verde" (guiso mejicano con pimiento o chile),

"salsa verde" (especie de salsa con harina y perejil).

"revolución verde" (mejoramiento en la producción agraria mediante el regadío, el uso de abonos y la mecanización en algunos países en vías de desarrollo),

Algunas de estas expresiones pueden tener connotaciones muy arraigadas en el pasado. El dicho "a buena(s) horas, mangas verdes", en opinión de algunos investigadores, se remonta a una época bastante lejana, la de los Reyes Católicos, cuando actuaban por los pueblos españoles las milicias de la Santa Hermandad, que vestidas de casacas con las mangas verdes, intentaban ayudar y socorrer a los necesitados. Las fuentes de la época aseguran, sin embargo, que, en la mayoría de lo casos, estos cuerpos de cuadrilleros llegaban demasiado tarde (véase Irribaren 1997: 88-89, Buitrago 2003: 14-15).

Hemos comentado que algunas de las unidades fraseológicas españolas con componente cromático tienen sus homófonos libres, como p.ej.:

"estar verde", "estar blanco", "estar negro", "un caballo blanco", "cascos azules", "tarjeta amarilla", "teléfono rojo", "matcria gris", "cruz roja", "tapete verde", etc.,

sin embargo, es dificil establecer todas las relaciones semánticas entre las unidades de este tipo, ya que son expresiones complejas, especializadas en alto grado, y que constituyen relativamente un pequeño grupo dentro del caudal léxico fraseológico de la lengua española.

Las unidades dobletes "el garabanzo negro" y "la oveja negra" las podemos considerar como sinónimos casi absolutos:

Pedro es el garabanzo negro de nuestra familia.

Pedro es la oveja negra de nuestra familia.

"Dar (tener) luz verde" y "dar (tener) carta blanca" pueden coincidir como sinónimos en algunos contextos, pero la verdad es que hay pocos ejemplos que 
cumplen estas relaciones. Se aproximan también semánticamente "estar verde" y "estar en blanco", mientras que en el caso de "poner verde a alguien" encontramos unidades del parecido campo semántico fuera de las unidades cromáticas, p.ej.: "poner como un trapo", "poner como chupa de dómine", "poner de vuelta y media", "poner como hoja de perejil", etc.

El tipo más rentable es, efectivamente, el de las expresiones comparativas afectivas que se establecen en la lengua siguiendo el mismo patrón sintagmático español: (... como ...) o (más ... que).

Veamos algunos ejemplos con los colores opuestos "blanco" y "negro", respectivamente:

[+pálido, +palidisimo]

blanco como un papel, blanco como la pared, blanco como un cadáver, blanco como un difunto, blanco como un mármol, blanco como un muerto, blanco que la cera.

Con sentido meliorativo tendríamos otra serie de comparaciones:

blanco como el jazmín, blanco como la nieve, blanco como el armiño, blanco como la leche, blanco como la azucena, blanco como el nardo;

más negro que (el azabache, el betún, el carbón, el ébano, la tinta, la endrina, la mora, etc.).

El juego de palabras entre el concepto moral negativo y la simbologia del color negro lo podemos ver claramente en este ejemplo:

"más negro que el alma de Judas"

(sobre las expresiones comparadas véase, Beinhauer 1978: 297-318).

Al finalizar este estudio inicial sobre las unidades fraseológicas españolas con componente cromático nos permitimos sacar unas conclusiones finales:

1. Hemos analizado tan sólo unas 200 unidades con componente cromático que hemos seleccionado de las obras lexicográficas modernas, cuyas referencias adjuntamos dentro de nuestra bibliografia.

2. Hemos prestado especial atención a las unidades con los colores "blanco" y "negro", que pertenecen en español a las más rentables. La oposición semántica entre las unidades con "blanco" y las con "negro" se mantiene fuerte, pero no es del 
todo "simétrica". El "negro" en las unidades fraseológicas tiene connotaciones preponderadamente negativas, es semánticamente más homogéneo que el blanco. Se puede observar una gran aportación de construcciones procedentes del lenguaje coloquial y del argot de los delincuentes.

3. El español no crea unidades que contengan componentes derivados de color como "rojizo", grisáceo, amarillento, azulado, etc., mientras que forma algunos compuestos del tipo "verdemar" (color semejante al verdoso que suele tomar el mar), "verdemontaña" (carbonato de cobre terroso de color verde claro).

4. Los significados conjuntos de las unidades con color pueden ser diversos y hasta contradictorios. Las unidades presentan diferentes tipos de fijación e idiomaticidad, desde las escasamente idiomáticas hasta las totalmente idiomáticas.

5. En muchos casos las metáforas resultan completamente opacas. Desde el punto de vista cognitivo, se nota la idiosincrasia española, única en su género.

6. Como hemos indicado, no todas las unidades con colores cálidos son significativamente positivas, buenas y optimistas.

7. Muchas expresiones españolas con elemento cromático suelen señalar y graduar algunas situaciones, cosas, fenómenos (unidades escalares). Por lo general, tienen su homófono libre.

8. Las relaciones semánticas típicas (p.ej., la sinonimia, la antonima) entre este tipo de unidades se dan en contados casos o son poco perceptibles por la complejidad de sus lexías complejas.

9. Son de mucha productividad las unidades comparativas de carácter afectivo.

\section{BIBLIOGRAFIAA}

Arcaini F. (1993), Universaux chromatiques et relativisme culturel. Analyse contrastive: domaines français et italien, Studia Romanica Posnaniensia XVII, págs. 7-56.

Beinhauer W. (1978), El español coloquial, Gredos, Madrid.

Buitrago A. (2003), Diccionario de dichos y frases hechas, Espasa Calpe, Madrid.

Diccionario Salamanca de la lengua española (1996), Santillana-Universidad de Salamanca, Madrid.

Irribarren J.M. (1997), El porqué de los dichos, Departamento de Educación y Cultura, Pamplona.

Kopaliński W. (2001), Slownik symboli. Oficyna Wydawniça Rytm, Warszawa.

Kurek M. (1997), Kolor w poezji Sianisława Grochowiaka, Poznaniskic Studia Polonistyczne, Seria Językoznawcza IV (XXIV), WiS. Poznań.

Lewicki A.M. (1982). O motywacji frazeologizmów, еп M. Basaj, D. Rytel (ed.), Z problemów frazcologii polskiej i slowianiskiej, I, Zaklad Narodowy im. Ossolińskich, Wrocław, págs. 33-47.

-, (1985), Motywacja globalna frazeologizmów, znaczenie przenośne. symboliczne i stereotypowe, on

M. Basaj. D. Rytel (ed.). Z problemów frazeologii polskiej i stowianskicj, III. Zaklad Narodowy im. Ossolińskich, Wydawnictwo PAN, Wrocław, págs. 7-23.

Marina J.A. (1999), La selva del lenguaje. Introducción a un diccionario de los sentimientos,

Editorial Anagrama, Barcclona. 
Pulido Ruiz J., Leniec-Lincow D. (2003), Idiomy polsko-hiszpańskie. Expresiones fraseologicas polaco-español, $\mathrm{PWN}$, Warszawa.

Sanmartín Sáez J. (1998), Diccionario de argot, Espasa Calpe, Madrid.

Si emianowska J. (2004), La simbologia de los colores expresada en las unidades fraseológicas en español. polaco e inglés, UAM (tesina de licenciatura), Poznań.

Suazo Pascual G. (1999), Abecedario de dichos y frases hechas, Editorial EDAF, Madrid.

Szałek J. (2005), La motivación en las unidades fraseológicas españolas, Estudios Hispánicos (en prensa).

Varela F., Kubarth H. (1994), Diccionario fraseologico del español moderno, Gredos, Madrid. 